\title{
Comprehensive Review
}

\section{Annals of \\ Neurosciences}

\section{Tetrabenazine: Spotlight on Drug Review}

\author{
Navneet Kaur ${ }^{\mathrm{a}}$ Puneet Kumar ${ }^{\mathrm{a}}$ Sumit Jamwal ${ }^{\mathrm{a}}$ Rahul Deshmukh ${ }^{\mathrm{a}}$ \\ Vinod Gauttam ${ }^{b}$ \\ ${ }^{a}$ Department of Pharmacology and ${ }^{b}$ Department of Pharmacognosy, ISF College of Pharmacy, Moga, India
}

\section{Key Words}

Huntington's chorea $\cdot$ Chorea $\cdot$ Treatment $\cdot$ Basal ganglia

\begin{abstract}
Background: Tetrabenazine (TBZ) is the only US Food and Drug Administration-approved drug for the treatment of chorea related to Huntington's disease and other hyperkinetic disorders. TBZ was first synthesized in 1950, and was then used for the treatment of psychosis. But later its potential in treating hyperkinetic disorders was proved by its ability to block vesicular monoamine transporters 2 and deplete monoamine stores. There is still lack of awareness about the therapeutic potential of this drug. Summary: TBZ had been approved only for the treatment of chorea, but several clinical studies have been conducted by different research groups and it was concluded that TBZ is effective in various other conditions such as tardive dyskinesia, dystonia, tics, and Tourette's syndrome, thus, highlighting the need for further clinical trials in these conditions. Key Message: The intention of this review is to sum up the information regarding chemistry, mechanism of action, pharmacokinetics, interactions, contraindications, adverse effects, and clinical efficacy of TBZ in diseases other than Huntington's chorea.

(c) 2016 S. Karger AG, Basel
\end{abstract}

(C) 2016 S. Karger AG, Basel

0972-7531/16/0233-0176\$39.50/0

\section{Introduction}

Tetrabenazine (TBZ) is a dopamine-depleting agent. It is the only US Food and Drug Administration (FDA)-approved drug for the treatment of chorea coupled with Huntington's disease (HD) and other hyperkinetic disorders [1]. In August 2008, TBZ was approved by US FDA for the treatment of chorea under the brand name xenazine. TBZ is also available in Europe and Australia under the name xenazine, and in Canada under the name nitoman. Other countries where TBZ is marketed are Denmark, France, Germany, Ireland, Israel, Italy, New Zealand, Portugal, Spain, Switzerland, and United Kingdom (UK) [2].

\section{History}

O. Schneider and A. Brossi initially synthesized TBZ in 1950s at the research laboratory of Hoffmann-La Roche in Basel. TBZ was approved for the treatment of psychoses/schizophrenia in Finland, Netherlands, UK, and Switzerland, but it was soon outmoded by phenothiazines because physicians declared phenothiazines more efficacious $[3,4]$. The effects of TBZ were similar to reserpine, which led to a clinical trial of TBZ in various involuntary movement disorders - such as Huntington's chorea,

\section{KARGER}

E-Mail karger@karger.com

www.karger.com/aon
Associate Prof. Dr. Puneet Kumar, MPharm, PhD

Department of Pharmacology

ISF College of Pharmacy

Moga, Punjab 142001 (India)

E-Mail punnubansal79@gmail.com 


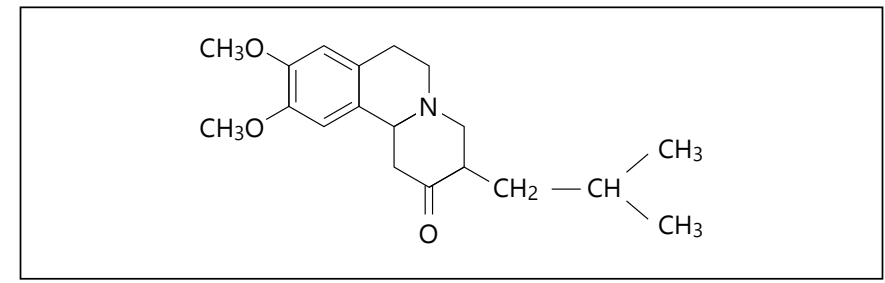

Fig. 1. Structure of TBZ

hemiballismus, Torsion dystonia, and facial dyskinesias [5-7]. Finally in August 2008, TBZ was approved by US FDA for the treatment of chorea.

\section{Chemistry}

The chemical structure of TBZ is shown in figure 1 . The chemical name of TBZ is $1,3,4,6,7,11 \mathrm{~b}$-hexahydro-9,10-dimethoxy-3-(2-methylpropyl)-2Hbenzo(a)quinolizin-2-one. TBZ has the molecular formula $\mathrm{C}_{19} \mathrm{H}_{27} \mathrm{NO}_{3}$ and its molecular weight is 317.43 .

\section{Chemical and Physical Properties}

TBZ is a white to light yellow crystalline powder with a bitter taste. It does not mix well with water, but is soluble in hot water, alcohol, and chloroform. Its melting range is $259-262^{\circ} \mathrm{F}$, and it has $\mathrm{pKa} 6.51$. Xenazine (TBZ) is supplied as a yellowish-buff scored tablet containing $25 \mathrm{mg}$ of TBZ, or as a white non-scored tablet containing $12.5 \mathrm{mg}$ of TBZ [8].

\section{Mechanism of Action}

Neurons consist of vesicles that store neurotransmitters, which are situated close to the end of each axon. Some neurotransmitters are synthesized directly in the vesicles whereas some others are synthesized in the cell body of neuron and subsequently shipped down into the vesicles for later release [9]. Due to storage inside vesicles, neurotransmitters have high levels in neurons and low levels in the synaptic cleft. This ensures a gradual and regulated release of neurotransmitters in the synaptic cleft from vesicles by the process of exocytosis [8]. Vesicular monoamine transporters (VMATs) are responsible for the translocation of cytosolic monoamines (serotonin, dopamine, norepinephrine, and histamine) into synaptic

TBZ: Spotlight on Drug Review vesicles in monoaminergic neurons [10]. There are 2 distinct subtypes of VMATs, namely VMAT1 and VMAT2. These subtypes have distinct pharmacological properties and tissue distribution. VMAT1 is mainly expressed in neuroendocrine cells and VMAT2 is chiefly expressed in the central nervous system (CNS) [11, 12]. Both reserpine and TBZ are considered as VMAT inhibitors.

TBZ is a potent VMAT2 blocker as shown in figure 2 . TBZ binds reversibly to VMAT2, thereby interrupting its function. This interruption in turn inhibits the uptake of monoamines and prevents dopamine release from vesicles. Its action lasts for 16-24 h. The greatest binding density for TBZ is in the caudate nucleus, nucleus accumbens, and, putamen areas [4]. Another mechanism by which TBZ acts is by blocking the presynaptic and postsynaptic dopamine receptors as shown in in vitro studies $[13,14]$. On the contrary, another monoamine depleter-reserpine-binds irreversibly to both VMAT1 and VMAT2. This makes reserpine's duration of action considerably longer. Due to its VMAT1 binding, reserpine shows peripheral adverse effects such as orthostatic hypotension and diarrhea $[2,15]$.

\section{Pharmacokinetics}

TBZ can be administered without any concern about food since trials have shown that the mean peak plasma concentration $\left(\mathrm{C}_{\max }\right)$ or area under the curve concentration is not affected by the administration of food following a single dose of TBZ [8]. TBZ undergoes rapid firstpass metabolism by hepatic carbonyl reductase to $2 \mathrm{com}$ pounds: alpha-dihydrotetrabenazine $(\alpha-\mathrm{HTBZ})$ and beta-dihydrotetrabenazine ( $\beta$-HTBZ), which in turn are metabolized by cytochrome 2D6 (CYP2D6)-mediated Odemethylation. The $\alpha-\mathrm{HTBZ}$ metabolite is active, while the $\beta$-HTBZ metabolite is chemically inert [16].

Oral bioavailability of TBZ was found to be in the range of $0.049 \pm 0.032$ and the mean absorption time was $481 \pm 50 \mathrm{~min}$ [17]. After administration of single doses from 12.5 to $50 \mathrm{mg}$ of TBZ, the maximum plasma concentration and the area under the curve for the metabolites $\alpha$ - and $\beta$-HTBZ increased approximately in proportion to the dose, which indicated linear kinetics [18].

A single oral dose of TBZ has been shown in clinical testing to undergo extensive ( $>75 \%)$ absorption from the gastro-intestinal tract. After oral administration, however, due to a high first-pass metabolism, the systemic bioavailability of TBZ is low but absorption is rapid within $1 \mathrm{~h} \mathrm{[8].} \mathrm{Both} \mathrm{forms} \mathrm{of} \mathrm{HTBZ} \mathrm{are} \mathrm{less} \mathrm{protein} \mathrm{bound} \mathrm{and}$ have a high bioavailability than TBZ. Protein binding of 


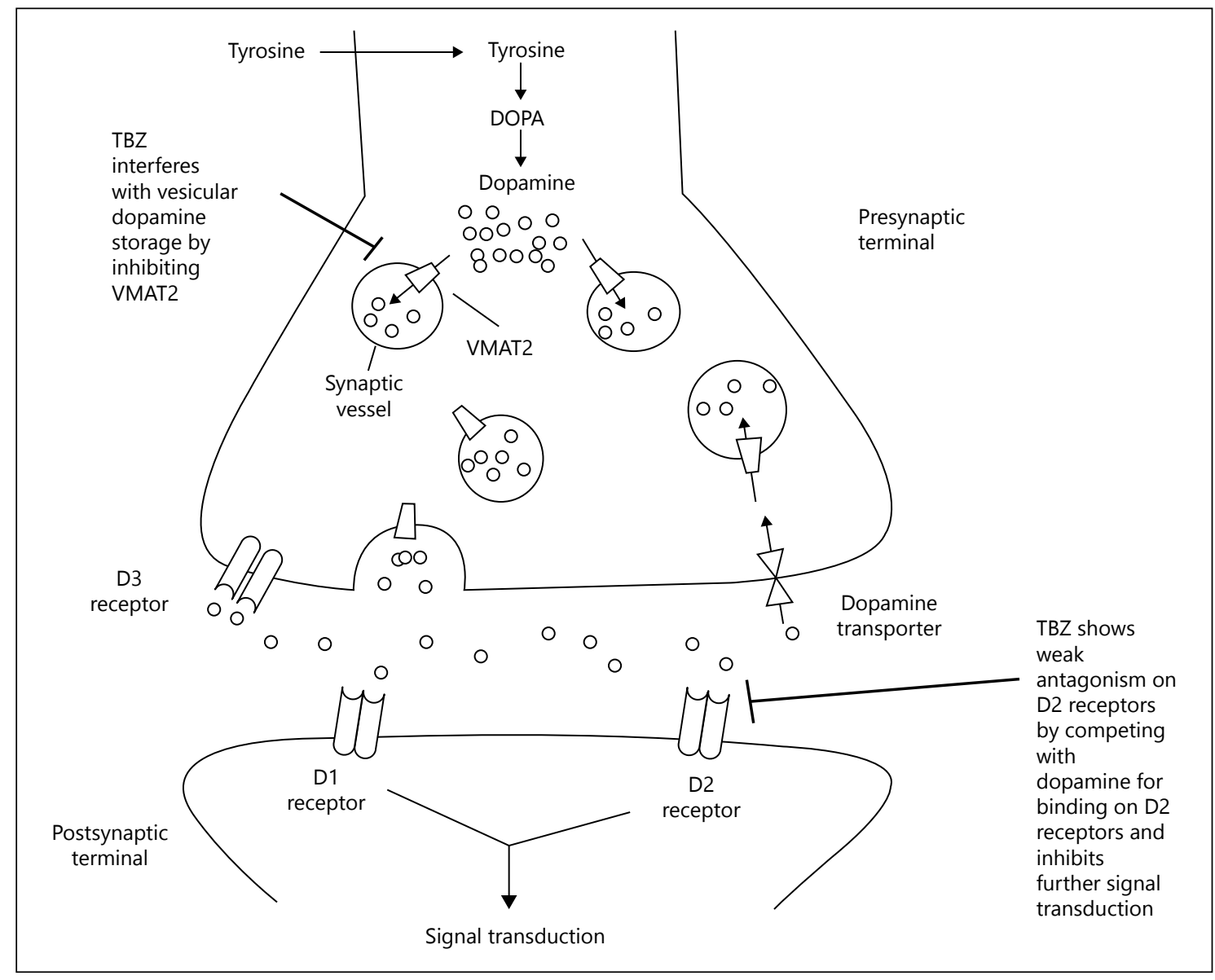

Fig. 2. Mechanism of action of TBZ.

HTBZ forms is $44-59 \%$ and TBZ is $83-88 \%$ [17]. TBZ has a half-life $\left(\mathrm{t}^{1} / 2\right)$ of $10 \mathrm{~h}$ whereas its metabolites $\alpha$-HTBZ and $\beta$-HTBZ have a half-life $\left(\mathrm{t}^{1} / 2\right)$ of $2-8$ and $2-5 \mathrm{~h}$, respectively [16]. At clinically appropriate concentrations in vivo, TBZ and its $\alpha-\mathrm{HTBZ}$ or $\beta$-HTBZ metabolites are not likely to be a substrate or inhibitor of P-glycoprotein and do not inhibit or induce CYP enzymes [8].

TBZ gets metabolized after oral administration, and the metabolites eliminate primarily via the renal route. A mass balance study was conducted in 6 healthy volunteers. According to the data obtained, the excretion of $75 \%$ (approximately) of the dose was through urine and approximately $7-16 \%$ was by fecal recovery. No TBZ in the unchanged form has been found in human urine [8]. In urinary excretion, less than $10 \%$ of the administered dose has been reported from $\alpha-\mathrm{HTBZ}$ or $\beta$-HTBZ. Rest of the metabolites consists of circulating metabolites, including sulfate and glucuronide conjugates of HTBZ metabolites and oxidative metabolism products [19].

\section{Dosage Administration}

\section{Individualized Dosing in Adults}

The dose for an individual patient should be titrated carefully to select the most suitable dose. The individualized dose can be selected by titrating the dose weekly until that dose is observed which seems beneficial for controlling chorea and is well tolerated [20]. Initial recommended dose of TBZ is $12.5 \mathrm{mg}$ once daily in the morning. Then a dose of $12.5 \mathrm{mg}$ twice a day in the morning and evening is used in the subsequent week. The dose should be increased by $12.5 \mathrm{mg}$ every week till the best effective and tolerated dose is selected [16]. If any patient needs more than 37.5-50 mg TBZ dose per day, then the dosing should be divided in regimen of 3 times a day [21]. Maximum limit for each dose is $25 \mathrm{mg}$. Patients who require more than $50 \mathrm{mg} /$ day should be tested for CYP2D6 genotype. More than $100 \mathrm{mg} /$ day of TBZ is not advised for any patient [22]. 
Tapering of dose is not required for the discontinuation of TBZ therapy. Chorea can recur within $12-18 \mathrm{~h}$ after taking the last dose of TBZ. Re-titration of TBZ dose is required if the treatment is suspended for more than 5 days. But if the treatment is resumed within 5 days, then there is no need for re-titration, and the previous maintenance dose can be selected [21].

\section{Dosing Recommendations Above $50 \mathrm{mg} /$ day in \\ Extensive/Intermediate Metabolizers}

Similar method of titration will be followed by increasing the dose weekly by $12.5 \mathrm{mg}$ till the effective and tolerated dose is selected. Doses should be divided into 3 times a day regimen. One hundred milligrams is considered as the maximum recommended daily dose and $37.5 \mathrm{mg}$ is considered as the maximum single dose for this group [19].

\section{Dosing Recommendations Above $50 \mathrm{mg}$ /day in Poor Metabolizers}

The method of titration is the same as that of extensive or intermediate metabolizers. The only difference is in the maximum recommended daily dose and maximum single dose. Fifty milligrams is considered as the maximum recommended daily dose and $25 \mathrm{mg}$ is considered as the maximum single dose for this group [19].

\section{Adverse Effects of TBZ}

The common side effects of TBZ are somnolence, acute akathisia, insomnia, fatigue, agitation, depression, anxiety, nausea, diarrhea, and parkinsonism [16, 23]. These side effects can be controlled by titrating or reducing the dose of TBZ. Because of this reason, these side effects are termed as dose limiting side effects [3].

Other types of side effects are rare and include panic attacks, orthostatic hypotension, mental problems, balance and gait difficulties, hallucinations, confusion, 'trance-like/zombie', blurred vision, dizziness, headaches, paresthesias, paranoia, pharyngeal spasm, and pain [24].

TBZ leads to serious risks such as suicidal ideation, depression, and neuroleptic malignant syndrome (NMS). TBZ is available with black box warning because TBZ can result in depression or can deteriorate an already present depression [20]. A controlled trial conducted in HD included 54 patients, out of which $19 \%$ were receiving TBZ; $19 \%$ of the total 54 patients showed occurrence of depression whereas in placebo group none of the patients experienced depression. Moreover, suicide was committed by one patient and suicidal ideation was experienced by one patient. However, in the placebo group no prevalence of these effects was found [25].

\section{Special Populations Pregnancy}

In humans, no specific well controlled studies have been conducted during pregnancy, so evidences for safety are not present. TBZ crosses placenta, therefore it should not be prescribed during pregnancy. TBZ is classified as pregnancy category $\mathrm{C}$ drug [21].

\section{Lactating Mothers}

TBZ is also secreted in breast milk, but it is not clearly identified that it is TBZ or its metabolite that is secreted in human milk. The choice about discontinuing the TBZ therapy should be made according to the condition of patient $[20,21]$.

\section{Pediatrics}

Limited published reports are available regarding the effects of TBZ on the pediatric population. In a study, 5 children of age between 22 months and 10 years, suffering from severe chorea; were administered with TBZ. It was reported that chorea was efficiently controlled and TBZ was well tolerated by 4 patients, but comparatively high doses were required [26].

\section{Geriatrics}

No specific controlled studies have been conducted in the geriatric population [20].

\section{Renal Insufficiency}

No controlled pharmacokinetic studies have been performed in patients with renal impairment [27].

\section{Hepatic Insufficiency}

A study compared 12 patients having liver disease (mild to moderate) with Child-Pugh scores of 5-9 and 12 normal healthy subjects of same age and gender; and a dose of $25 \mathrm{mg}$ of TBZ was administered [19]. Metabolism of TBZ to its metabolite was decreased in hepatically impaired patients. The plasma concentration of TBZ was either the same or more in the group of hepatic disease patients as compared to normal subjects. The elimination half-life of TBZ was extended to $17.5 \mathrm{~h}$ and of $\alpha-\mathrm{HTBZ}$ and $\beta-\mathrm{HTBZ}$ was extended up to 10 and $8 \mathrm{~h}$, respectively in hepatically impaired group. The main TBZ peak concentration $\left(\mathrm{C}_{\max }\right)$ was found to be 7-190 folds greater in the group with hepatic disease than that of normal subjects. On the whole, the exposure of metabolites of TBZ ( $\alpha-\mathrm{HTBZ}$ and $\beta-\mathrm{HTBZ}$ ) 
was more (30-39\% approximately) in patients with hepatic impairment as compared to the healthy group [19].

TBZ is contraindicated in patients with liver disease as it is not feasible to adjust the dosage of TBZ to ensure safe use.

\section{Drug Interactions}

- The metabolites of TBZ, $\alpha-H T B Z$ and $\beta$-HTBZ, are metabolized by isoenzyme CYP2D6. The concomitant use of TBZ with CYP2D6 inhibitors and inducers can affect the metabolism of these metabolites. Dose reduction of TBZ is necessary when CYP2D6 inhibitors (paroxetine, fluoxetine, quinidine) are administered to a patient who is already on TBZ therapy. The maximum single dose of TBZ should not exceed $25 \mathrm{mg}$ and the daily dose should not exceed $50 \mathrm{mg}$ per day in patients taking strong inhibitors of CYP2D6 isoenzyme [16, 21, 27].

- Both reserpine and TBZ are VMAT2 inhibitors; thus, their concomitant use should be avoided. Caution should be taken when changing the therapy from reserpine to TBZ for any patient because of longer action duration and irreversible binding of reserpine to VMAT2. A period of 20 days is recommended between stopping of reserpine therapy and before starting of TBZ therapy $[8,23]$.

- The use of TBZ in combination with neuroleptics, antibiotics, Class IA and III antiarrhythmics increases the risk of QTc prolongation. Additionally, extrapyramidal effects and NMS are also observed in cases of concomitant use of TBZ with neuroleptics [23].

- Several drug interactions of TBZ have been reported with antidepressant drugs. Concomitant use of TBZ and monoamine oxidase inhibitors (MAOIs) can lead to CNS toxicity including confusion, restlessness, and behavioral alterations [27]. Use of TBZ along with tricyclic antidepressants can antagonize TBZ-induced locomotor activity in animals $[20,28]$.

- Co-administration with alcohol may worsen the sedation caused by TBZ [21].

- TBZ should be cautiously administered along with antihypertensives and $\beta$-blockers, because it may enhance the danger of orthostatic hypotension [20].

\section{Indications}

TBZ has been approved by US FDA for the treatment of HD-related chorea.

\section{Contraindications}

TBZ is contraindicated in patients who are vigorously suicidal, or patients without treatment or with insufficiently treated depression [23]. TBZ is also contraindicated in patients having weakened hepatic function. TBZ administration along with reserpine and MAOIs is contraindicated because it may worsen the condition [19]. TBZ should not be administered before 14 days of discontinuing MAOI therapy and not before 20 days of discontinuing reserpine therapy. The combination of TBZ and alcohol is contraindicated due to additive sedation [21].

\section{Warnings and Precautions}

Dosage of TBZ in patients should be considered cautiously. The need for TBZ therapy should be re-examined once in a while in patients by checking the advantageous effects on chorea and the symptoms due to worsening of disease [23]. The dose should be quantified carefully up to the dose that is beneficial in patient because some of the observed side effects are dependent on dose [21]. To increase the daily dose of patient above $50 \mathrm{mg}$, CYP2D6 gene should be tested for the metabolic nature of the patient. If the patient is a poor metabolizer, then the exposure will be considerably higher after taking TBZ ( $\alpha-\mathrm{HTBZ}$ by 3 -fold and $\beta$-HTBZ by 9 -fold) as compared to extensive or intermediate metabolizers [19].

TBZ has the potential to cause NMS because of its dopamine transmission reducing ability. The clinical manifestations of this syndrome include mental changes, muscle rigidity, hyperpyrexia, autonomic dysfunction (irregular blood pressure and sweating), and raised creatinine phosphokinase levels [20]. TBZ can worsen depression and suicidal thoughts, due to which it comes with a black box warning.

\section{Clinical Studies in Movement Disorders}

Huntington's Chorea

Evidence of therapeutic potential of TBZ in HD chorea was initially published in 1960s [5, 29, 30]. Since then, several long- and short-term studies have been conducted and published that proves the beneficial role of TBZ in chorea patients [3].

\section{Short-Term Studies}

A study in 2006 was conducted by the Huntington's study group, which was a multicenter double-blind, randomized, placebo-controlled trial of 12 weeks to check 
the safety, tolerability, and efficacy of TBZ for the treatment of chorea. A total of 84 patients aged 27-77 years having a score of $>5$ on Total Functional Capacity Scale and a score of $\geq 10$ on Unified Huntington's Disease Rating Scale (UHDRS) were enrolled in the trial. Fifty four patients were randomly included in the TBZ group and the remaining 30 patients were included in the placebo group. The starting dose was $12.5 \mathrm{mg} / \mathrm{day}$, which was then increased every week by $12.5 \mathrm{mg}$ till the 7 th week until the chorea was efficiently controlled, intolerable side effects came up or a dose of $100 \mathrm{mg} /$ day was reached. This was considered as the titration period. Then the dose was left unaltered for the remaining 5 weeks until the patient became intolerable to the adverse effects, and this period was considered as the maintenance period. On UHDRS, alteration from baseline in the total maximal chorea score was measured as the chief efficacy outcome. TBZ group showed a decrease of 5.0 units in chorea and placebo group showed a reduction of 1.5 units as compared to the baseline. On Clinical Global Impressions Improvement Scale, $24 \%$ of subjects of placebo group attained a score of $\leq 3$ as compared to $69 \%$ of subjects of TBZ group. This finding also suggested superiority of the TBZ group over the placebo group. At the end of the washout period, no distinction between TBZ and placebo groups was observed when compared in terms of baseline for cognitive, motor, and behavioral severity. In the treatment group, stopping the TBZ therapy worsened the existing chorea. TBZ was well tolerated by all the subjects. However, insomnia and drowsiness were common adverse effects. Moreover, dose was decreased in some cases as 2 patients reported depressed mood, 2 patients reported parkinsonism, and 4 patients reported akathisia. One subject of TBZ group committed suicide during the study, but his rating on the Hamilton Depression Scale was normal from previous assessments [31].

Another short-term study was conducted in 2007 by Kenney et al. [32]. Ten patients were included in this study (range between 35 and 71 years of age). The included patients had enough disability due to chorea for it to be measured. Inclusion in the study required stable TBZ dosing in subjects. Last dose of TBZ was given in the evening to the subjects and they were included in the study the subsequent day. Baseline assessment was done after $12 \mathrm{~h}$ of last evening dose. UHDRS motor assessment and Beck Depression Inventory was used for baseline assessment. Then the morning dose was administered to the subjects and assessment was done after every $2 \mathrm{~h}$ with UHDRS until the baseline chorea re-emerged. After the TBZ administration, UHDRS chorea score diminished on an average by $42.4 \pm 17.8 \%$. The mean duration of ef-

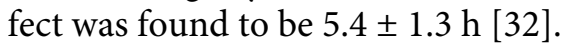

In 2008, another short-term, randomized, double blind study was performed and published by Frank et al. [33]. This study proved that chorea re-emerges after the withdrawal of TBZ due to short half-life. Thirty patients (ages between 39 and 75 years) who were taking TBZ for the previous 2 months were enrolled in the study. The study lasted for 5 days. Participants were randomly divided into 3 different groups. The first group was the withdrawal group with 12 patients, in which TBZ was withdrawn on the 1st day of study. The second group was a partial withdrawal group with 12 patients, where TBZ was withdrawn on the 3rd day. In the last group that consisted of 6 patients, there was no withdrawal. This group remained on TBZ all 5 days. The UHDRS chorea scores were increased by 5.3 units from 1st to 3 rd day in subjects from the withdrawal group. On the contrary, the UHDRS scores of partial or no withdrawal group were increased by 3.0 units $(p=0.0773)$. A post-hoc analysis illustrated a linear trend for the re-emergence of chorea $(p=0.0486)$ [33].

\section{Long-Term Studies}

A long-term retrospective study was conducted by Fasano et al. [34] in 2008. Sixty eight HD patients having mean disease duration of $55.8 \pm 34.7$ months and mean age at onset of HD of $43.3 \pm 11.8$ years were included in the study. TBZ dose was increased weekly up to a maximum dose of $150 \mathrm{mg} /$ day. Patients treated with TBZ had $35.3 \pm 14.7 \mathrm{mg}$ as mean dose at first follow-up and had $57.5 \pm 14.7 \mathrm{mg}$ as mean dose at last follow-up. The baseline for UHDRS motor scale was noted as 39.4 out of 120 and the mean UHDRS chorea score was noted as 10.4 out of 28 . The mean UHDRS chorea score was $8.2 \pm 4.1$ during the first follow-up and was $9.5 \pm 5.0$ during the last followup. This showed a significant reduction as compared to the baseline score. TBZ dose was increased by $63 \%$, and the mean UHDRS motor scores showed an increase by $32 \%$ as compared to the baseline. Thirty four patients stated at least one side effect from the most common ones and 2 patients withdrew from the study due to side effects (psychiatric disturbance and asthenia). TBZ was discontinued in 5 patients due to lack of any beneficial effect [34].

\section{Tardive Dyskinesia}

The American Psychiatric Association Task Force defined tardive dyskinesia (TD) as an abnormal involuntary hyperkinetic movement, which occurs in a patient taking neuroleptic treatment (minimum of 3 months) with no additional particular basis for movement disorders [35]. 
Table 1. Clinical trials of TBZ in TD

\begin{tabular}{|c|c|c|c|c|}
\hline Study design & Numbers & $\begin{array}{l}\text { Mean TBZ } \\
\text { dosage, mg/day }\end{array}$ & Outcome & Study \\
\hline $\begin{array}{l}\text { Randomized, double-blind, } \\
\text { crossover versus placebo }\end{array}$ & 6 & 100 & $\begin{array}{l}50 \% \text { patients from TBZ group had improved movements as } \\
\text { compared to } 0 \% \text { from placebo group }\end{array}$ & {$[50]$} \\
\hline $\begin{array}{l}\text { Open-label, single-blind, crossover } \\
\text { versus placebo }\end{array}$ & 24 & 122.5 & $\begin{array}{l}\text { Abnormal movements were vanished in } 33 \% \text { patients and } \\
\text { were attenuated in } 25 \% \text { patients }\end{array}$ & {$[51]$} \\
\hline $\begin{array}{l}\text { Randomized, double-blind, } \\
\text { placebo-controlled, crossover }\end{array}$ & 4 & 200 & $100 \%$ patients showed improvement & {$[53]$} \\
\hline Open-label & 23 & 91.3 & $100 \%$ patients showed improvement in movement & {$[54]$} \\
\hline Retrospective & 17 & Not reported & $41 \%$ patients showed improvement in movement & {$[56]$} \\
\hline Retrospective & 149 & Not reported & $84 \%$ patients showed improvement & {$[57]$} \\
\hline
\end{tabular}

There was continuous exposure to dopamine receptor blocking agents such as neuroleptic drugs (typical and atypical), antiemetics and agents used for disorders of gastrointestinal tract (e.g., promethazine and metoclopramide), calcium channel blockers (flunarizine, cinnarizine), and tricyclic antidepressants (e.g., amoxapine) [36]. The term includes various phenotypes such as stereotypy, dystonia, akathisia, orofacial lingual movements, myoclonus, and tremors [28].

Several small, blinded, randomized trials were carried out to check the efficacy of different drugs in TD and TBZ is one of them. Since 2008, after the FDA approval for the use of TBZ in Huntington's chorea, TBZ became the drug of choice for the treatment of moderate to severe condition of TD [37]. Several studies were conducted to check the effectiveness of TBZ in TD and are discussed in table 1 .

TBZ is well tolerated in terms of safety. It has a short half-life and moreover, most of the adverse effects such as parkinsonism, depression, drowsiness related to TBZ are dose limiting. So TBZ may emerge as a safe drug for different phenotypes of TD in future [38].

\section{Tic and Tourette's Syndrome}

'Tic disorder' is a term coined for a medical state which embodies a particular form of repetitive, nonrhythmically recurrent, stereotyped, chiefly involuntary movement [39]. The American Psychiatric Association published The Diagnostic and Statistical Manual of Mental Disorders (5th ed) in 2013 and enlisted Gilles de la Tourette syndrome (TS) as one of the key tic disorder [40]. The indications of TS are wide-ranging including motor and non-motor (emotional and cognitive abnormalities) disturbances. Motor and vocal tics for more than 1 year with tic-free phase of less than 3 successive months are prominent diagnostic attributes of TS, which start up sooner than the age of $18[39,41]$. Reports from the start of TS research suggest its connection with dopamine system dysfunctioning [42]. Agents such as $\alpha$-adrenergic agonists (e.g., clonidine), antipsychotics (typical and atypical), dopamine agonists (e.g., pergolide), anticonvulsants (e.g., topiramate) have been used to decrease the severity of TS, and TBZ is also one of them $[43,44]$. Various open-label, nonrandomized, retrospective studies have been carried out to check the efficacy of TBZ in the treatment of TS but the limitation is that no randomized, controlled study has been conducted. Studies conducted thus far are listed in table 2.

\section{Dystonia}

Dystonia is a neurological disorder identified by unnecessary, involuntary, repetitive sustained contraction of muscles, leading to twisting movements and unnatural 
Table 2. Clinical trials of TBZ in Tic and Tourette's syndrome

\begin{tabular}{|c|c|c|c|c|}
\hline $\begin{array}{l}\text { Non randomized, open-label, } \\
\text { crossover }\end{array}$ & 7 & 270 & Only $40 \%$ patients showed improvement & {$[58]$} \\
\hline Open-label, retrospective & 9 & 82 & $\begin{array}{l}78 \% \text { patients showed improvement, out of } \\
\text { which } 44 \% \text { patients had an improvement } \\
\text { duration for }>6 \text { months and } 33 \% \text { had for } \\
<6 \text { months }\end{array}$ & {$[59]$} \\
\hline Retrospective & 15 & Not reported & $80 \%$ patients showed improvement & {$[60]$} \\
\hline Retrospective & 17 & 81.6 & $94 \%$ showed improvement & {$[61]$} \\
\hline Retrospective & 47 & 83.5 & $57.4 \%$ patients showed improvement & {$[24]$} \\
\hline Open-label, prospective & 120 & 70.5 & $76 \%$ patients showed improvement & {$[62]$} \\
\hline
\end{tabular}

Table 3. Clinical trials of TBZ in dystonia

\begin{tabular}{|c|c|c|c|c|}
\hline Study design & Numbers & Mean TBZ dosage, mg/day & Outcome & Study \\
\hline Prospective, single-blind & 9 & 128 & Only $38 \%$ patients were improved & {$[7]$} \\
\hline $\begin{array}{l}\text { Double-blind, randomized, } \\
\text { placebo controlled, } \\
\text { crossover }\end{array}$ & 12 & 162.5 & $\begin{array}{l}\text { Improvement was seen in about } 92 \% \\
\text { patients }\end{array}$ & {$[53]$} \\
\hline Retrospective & 14 & $\begin{array}{l}\text { Adult: } 90 \\
\text { Pediatric: } 75\end{array}$ & $71 \%$ patients improved & {$[63]$} \\
\hline Retrospective & $\begin{array}{r}15 \\
19 \\
57 \\
25 \\
5 \\
3\end{array}$ & $\begin{array}{l}\text { Tardive dystonia: } 155.4 \\
\text { Generalized dystonia: } 114.5 \\
\text { Cranial dystonia: } 109 \\
\text { Focal dystonia: } 119 \\
\text { Essential blepharospasm: } 85 \\
\text { Hemidystonia: } 150\end{array}$ & $\begin{array}{l}\text { Marked or moderate improvement was } \\
\text { noticed in } 76 \% \text { patients }\end{array}$ & {$[61]$} \\
\hline Retrospective & 41 & Not reported & Improvement was seen in $49 \%$ patients & {$[56]$} \\
\hline Retrospective & 132 & 50.4 & $68 \%$ patients showed improvement & {$[57]$} \\
\hline
\end{tabular}

postures $[45,46]$. Dystonia can be classified on the basis of the age of onset (early and late), distribution (focal, segmental, multifocal, hemi, generalized), and cause (primary, secondary, as a mark of another neurologic disorder, pseudo dystonia) [47]. Treatment options available for dystonia include dopaminergic agents (e.g., levodopa), antidopaminergic agents (e.g., clozapine, TBZ), anticholinergics (e.g., trihexyphenidyl), muscle relaxants (e.g., clonazepam, baclofen), botulinum toxin, and deep brain stimulation of globus pallidus interna $[48,49]$. Some of the conducted studies are discussed in table 3 . 


\section{Other Disorders}

TBZ has been tested in various other disorders such as myoclonus and hemiballismus. Only a few studies have been performed in myoclonus, hemiballismus, and other movement disorders [24, 57]. More trials need to be conducted to check the effect of TBZ in these disorders.

\section{Conclusion}

TBZ, a VMAT2 blocker, diminishes monoamine stores. It has proven its potential through clinical trials in several hyperkinetic disorders including TD, tic and Tourette's syndrome, dystonia, and myoclonus. Currently, TBZ is only approved for the treatment of chorea in the US. Common side effects include insomnia, depression, parkinsonism, akathisia, and NMS.

\section{Acknowledgements}

Authors are grateful to Mr. Praveen Garg (Chairman, I.S.F. College of Pharmacy, Moga) for providing necessary resources and facilities. Authors are thankful to Science and Engineering Board (SERB), Department of Science and Technology, Government of India, New Delhi for providing financial assistance to Dr. Puneet Kumar under Fast Track Scheme (DST-SERB-FTYS).

\section{Authors Contributions}

N.K.: literature review, data collection, and article writing; S.J.: literature review, data collection, and article writing; R.D.: data interpretation and critical revision of article; P.K.: data interpretation and critical revision of article.

\section{Disclosure Statement}

The authors have no conflict of interest.

\section{References}

1 Shen V, Clarence-Smith K, Hunter C, Jankovic J: Safety and efficacy of tetrabenazine and use of concomitant medications during longterm, open-label treatment of chorea associated with Huntington's and other diseases. Tremor Other Hyperkinet Mov (N Y) 2013; 3:pii:tre-03-191-4337-1.

2 Frank S: Tetrabenazine: the first approved drug for the treatment of chorea in US patients with Huntington disease. Neuropsychiatr Dis Treat 2010;6:657-665.

3 Paleacu D: Tetrabenazine in the treatment of Huntington's disease. Neuropsychiatr Dis Treat 2007;3:545-551.

4 de Tommaso M, Serpino C, Sciruicchio V: Management of Huntington's disease: role of tetrabenazine. Ther Clin Risk Manag 2011;7: 123-129.

5 Brandrup E: Reserpinogtetrabenacinved chorea Huntington. Nord Med 1960;4:968-969.

6 Dalby MA: Effect of tetrabenazine on extrapyramidal movement disorders. Br Med J 1969:2:422-423.

7 Swash M, Roberts AH, Zakko H, Heathfield KW: Treatment of involuntary movement disorders with tetrabenazine. J Neurol Neurosurg Psychiatry 1972;35:186-191.

8 Yero T, Rey JA: Tetrabenazine (xenazine), an FDA-approved treatment option for Huntington's disease-related chorea. P T 2008;33: 690-694.

9 Lovinger DM: Communication networks in the brain: neurons, receptors, neurotransmitters, and alcohol. Alcohol Res Health 2008;31: 196-214.

10 Wimalasena K: Vesicular monoamine transporters: structure-function, pharmacology, and medicinal chemistry. Med Res Rev 2011; 31:483-519.

11 Fei H, Grygoruk A, Brooks ES, et al: Trafficking of vesicular neurotransmitter transporters. Traffic 2008;9:1425-1436.

12 Zheng G, Dwoskin LP, Crooks PA: Vesicular monoamine transporter 2: role as a novel target for drug development. AAPS J 2006; 8:E682-E692

13 Login IS, Cronin MJ, MacLeod RM: Tetrabenazine has properties of a dopamine receptor antagonist. Ann Neurol 1982;12:257262.

14 Reches A, Burke RE, Kuhn CM, Hassan MN, Jackson VR, Fahn S: Tetrabenazine, an aminedepleting drug, also blocks dopamine receptors in rat brain. J Pharmacol Exp Ther 1983; 225:515-521.

15 Schuldiner S, Liu Y, Edwards RH: Reserpine binding to a vesicular amine transporter expressed in Chinese hamster ovary fibroblasts. J Biol Chem 1993;268:29-34.

16 Chen JJ, Ondo WG, Dashtipour K, et al: Tetrabenazine for the treatment of hyperkinetic movement disorders: a review of the literature. Clin Ther 2012;34:1487-1504.

17 Roberts MS, McLean S, Millingen KS, Galloway HM: The pharmacokinetics of tetrabenazine and its hydroxy metabolite in patients treated for involuntary movement disorders. Eur J Clin Pharmacol 1986;29: 703-708.

18 Mehvar R, Jamali F, Watson MW, Skelton D: Pharmacokinetics of tetrabenazine and its major metabolite in man and rat. Bioavailability and dose dependency studies. Drug Metab Dispos 1987;15:250-255.
19 Product Information. Xenazine (Tetrabenazine). Deerfield, Ovation Pharmaceuticals, Inc., 2008.

20 Product Information. Tetrabenazine Tablets: iNOVA Pharmaceuticals (Aust) Pty Ltd., 1991.

21 Prescribing Xenazine (Tetrabenazine) Tablets: A Healthcare Professional Guide. Approved by FDA as a Part of the Xenazine Risk Evaluation and Mitigation Strategy, 2008.

22 Pidgeon C, Rickards H: The pathophysiology and pharmacological treatment of Huntington disease. Behav Neurol 2013;26:245253

23 Chitnis S, Karunapuzha CA: Tetrabenazine in Huntington's disease chorea. Clin Med Ther 2009;1:669-681.

24 Jankovic J, Beach J: Long-term effects of tetrabenazine in hyperkinetic movement disorders. Neurology 1997;48:358-362.

25 Food and Drug Administration, Center for Drug Evaluation and Research: Application No. 21-894: Tetrabenazine. Medical Review (Online). www.fda.gov (accessed October 20 2008).

26 Chatterjee A, Frucht SJ: Tetrabenazine in the treatment of severe pediatric chorea. Mov Disord 2003;18:703-706.

27 Poon LH, Kang GA, Lee AJ: Role of tetrabenazine for Huntington's disease-associated chorea. Ann Pharmacother 2010;44:10801089.

28 Fasano A, Bentivoglio AR: Tetrabenazine. Expert Opin Pharmacother 2009;10:2883-2896.

29 Sattes H: [The treatment of chorea minor with the monoamine liberator 'nitoman'] Psychiatr Neurol (Basel) 1960;140:13-19. 
30 Sattes H, Hase E: Die behandherd extrapyramidaler hypokinesien unto besonderer beriicksichtigung der chorea Huntington. Psychiatr Neurol Neurochirurg (Aust) 1964;67:289.

31 Huntington Study Group: Tetrabenazine as antichorea therapy in Huntington disease: a randomized controlled trial. Neurology 2006; 66:366-372.

32 Kenney C, Hunter C, Davidson A, et al: Shortterm effects of tetrabenazine on chorea associated with Huntington's disease. Mov Disord 2007;22:10-13.

33 Frank S, Ondo W, Fahn S, Hunter C, Oakes D, Plumb S, Marshall F, Shoulson I, Eberly S, Walker F, Factor S, Hunt V, Shinaman A Jankovic J: A study of chorea after tetrabenazine withdrawal in patients with Huntington disease. Clin Neuropharmacol 2008;31:127133.

34 Fasano A, Cadeddu F, Guidubaldi A, Piano C, Soleti F, Zinzi P, Bentivoglio AR: The longterm effect of tetrabenazine in the management of Huntington disease. Clin Neuropharmacol 2008;31:313-318.

35 Tardive dyskinesia: summary of a task force report of the American psychiatric association. By the task force on late neurological effects of antipsychotic drugs. Am J Psychiatry 1980;137:1163-1172.

36 Waln O, Jankovic J: An update on tardive dyskinesia: from phenomenology to treatment. Tremor Other Hyperkinet Mov (N Y) 2013 3:pii:tre-03-161-4138-1.

37 Cloud LJ, Zutshi D, Factor SA: Tardive dyskinesia: therapeutic options for an increasingly common disorder. Neurotherapeutics 2014; 11:166-176.

38 Aquino CC, Lang AE: Tardive dyskinesia syndromes: current concepts. Parkinsonism Relat Disord 2014;20(suppl 1):S113-S117.

39 Roessner V, Schoenefeld K, Buse J, Bender S, Ehrlich S, Münchau A: Pharmacological treat- ment of tic disorders and Tourette syndrome. Neuropharmacology 2013;68:143-149.

40 American Psychiatric Association: Diagnostic and Statistical Manual of Mental Disorders, 5th Edition: DSM-5. American Psychiatric Association, 2013.

41 Gilbert DL, Jankovic J: Pharmacological treatment of Tourette syndrome. J Obsessive Compuls Relat Disord 2014;3:407-414.

42 Mogwitz S, Buse J, Ehrlich S, Roessner V: Clinical pharmacology of dopamine-modulating agents in Tourette's syndrome. Int Rev Neurobiol 2013;112:281-349.

43 Hartmann A: Clinical pharmacology of nondopaminergic drugs in Tourette syndrome. Int Rev Neurobiol 2013;112:351-372.

44 Shaw ZA, Coffey BJ: Tics and Tourette syndrome. Psychiatr Clin North Am 2014;37: 269-286.

45 Jinnah HA, Hess EJ: Experimental therapeutics for dystonia. Neurotherapeutics 2008; 198-209.

46 Silverdale MA: Other movement disorders. Medicine 2012;40:536-539.

47 Kartha N: Dystonia. Clin Geriatr Med 2006; 22:899-914, vii.

48 Jankovic J: Treatment of dystonia. Lancet Neurol 2006;5:864-872.

49 Kartha N: Therapeutic challenges in dystonia. Neurol Clin 2010;28:927-940.

50 Godwin-Austen RB, Clark T: Persistent phenothiazine dyskinesia treated with tetrabenazine. Br Med J 1971;4:25-26.

51 Kazamatsuri H, Chien C, Cole JO: Treatment of tardive dyskinesia. I. Clinical efficacy of a dopamine-depleting agent, tetrabenazine. Arch Gen Psychiatry 1972;27:95-99.

52 Asher SW, Aminoff MJ: Tetrabenazine and movement disorders. Neurology 1981;31: 1051-1054.

53 Jankovic J: Treatment of hyperkinetic movement disorders with tetrabenazine: a double- blind crossover study. Ann Neurol 1982;11: 41-47.

54 Watson MW, Skelton D, Jamali F: Treatment of tardive dyskinesia: preliminary report on use of tetrabenazine. Can J Psychiatry 1988; 33:11-13.

55 Ondo WG, Hanna PA, Jankovic J: Tetrabenazine treatment for tardive dyskinesia: assessment by randomized videotape protocol. Am J Psychiatry 1999;156:1279-1281.

56 Paleacu D, Giladi N, Moore O, et al: Tetrabenazine treatment in movement disorders. Clin Neuropharmacol 2004;27:230-233.

57 Kenney C, Hunter C, Jankovic J: Long-term tolerability of tetrabenazine in the treatment of hyperkinetic movement disorders. Mov Disord 2007;22:193-197.

58 Sweet RD, Bruun R, Shapiro E, et al: Presynaptic catecholamine antagonists as treatment for Tourette syndrome. Effects of alpha methyl para tyrosine and tetrabenazine. Arch Gen Psychiatry 1974;31:857-861.

59 Jankovic J, Glaze DG, Frost JD Jr: Effect of tetrabenazine on tics and sleep of Gilles de la Tourette's syndrome. Neurology 1984;34: 688-692.

60 Jankovic J, Rohaidy H: Motor, behavioral and pharmacologic findings in Tourette's syndrome. Can J Neurol Sci 1987;14(3 suppl):541-546.

61 Jankovic J, Orman J: Tetrabenazine therapy of dystonia, chorea, tics, and other dyskinesias. Neurology 1988;38:391-394.

62 Porta M, Sassi M, Cavallazzi M, Fornari M, Brambilla A, Servello D: Tourette's syndrome and role of tetrabenazine: review and personal experience. Clin Drug Investig 2008;28: 443-459.

63 Marsden CD, Marion MH, Quinn N: The treatment of severe dystonia in children and adults. J Neurol Neurosurg Psychiatry 1984; 47:1166-1173. 